\title{
FORMACIÓN PARA EL RENDIMIENTO (CAPITAL HUMANO) Y EDUCACIÓN COMO HEREJÍA: CIENCIAS SOCIALES Y BIOPOLÍTICA
}

TRAINING FOR THE PERFORMANCE (HUMAN CAPITAL) AND EDUCATION AS HERESY: SOCIAL SCIENCES AND BIO POLITICS

\section{Javier Numan Caballero Merlo ${ }^{1}$}

Enviado: $14 / 3 / 2021$ Aceptado: 25/4/2021

Resumen: El problema analizado emerge como contracara de los diversos y complejos procesos sociales virulentos, disparados a partir de la actual pandemia como dato consumado. Instalándose políticas, discursos y prácticas en las que la ciudadanía solo se dejó llevar como por el cauce de un raudal, contestando a la impostura únicamente por reflejo a la misma. Establecido el precedente, se abre la puerta a la invocación recurrente a la pandemia, y al mismo tiempo, paranoicamente a otro virus futuro probable, de manera cíclica, como recordatorio y justificación (legitimidad) 
para conducir conductas (gobierno) utilizando un tema muy específico de salud; sin embargo, esparciéndose y afectando a todos los ámbitos de la sociedad. Como objetivos se hacen explícitos los efectos de saber-poder, causas y consecuencias de la aplicación de ciertos dispositivos que invaden y normalizan simultáneamente a la sociedad en su conjunto y a cada individuo. Así como, ante el miedo normal de la mayoría de la ciudadanía frente a la posibilidad de muerte, aunque esta sea limitada objetivamente como se verá, se avanza con desproporcionalidad en la invasión de la vida social tanto particular como colectiva, en una extensión de acciones de gobierno más allá de lo estrictamente sanitario. Se han considerado indicadores educativos intervinientes en el ejercicio de la ciudadanía y su empoderamiento cívico como clave de protección y garantía de los derechos fundamentales. También algunos números respecto a la pandemia y sobre la mortalidad que permiten dimensionar la desproporcionalidad, así como qué puede haber más allá de la excusa sanitaria para tanto despliegue gubernamental. Y, finalmente, una problematización del objeto de estudio del ejercicio docente en ciencias sociales, como núcleo del pánico, entrelazando la asociación negativa entre las relaciones sociales con el distanciamiento social. El método ha sido cualitativo, con base en el análisis documental comparativo. Los resultados muestran cómo en una coyuntura de riesgo sanitario, se aprovecha política y estratégicamente la oportunidad desde la biopolítica para una ampliación, profundización y aceleramiento sin precedentes en la aplicación de estrategias y tácticas de disciplinamiento social más eficientes y eficaces que aquellas del inicio de la modernidad. Necesarias, desde el sistema, y para el desarrollo del capital, para que el ser 
humano sin propiedad se transformase en trabajador útil y dócil, y a su vez, políticamente consecuente. Eso es lo que se denomina construcción de procesos de hegemonía para el ejercicio legítimo de la dominación. Las tecnologías del yo (Foucault, 1990) perfeccionan la internalización de las estructuras sociales externas de manera inconsciente en el contexto de la modernidad tardía neoliberal a través del psico-poder, usando el dataísmo y la ilussio de libertad en el rendimiento del improve yourself. (Han, 2014a). Hasta el intento de redefinir la práctica misma y el concepto de relación clave de la vida social, expresada de diversas maneras como distanciamiento social; cuando, de lo que se trata aquí, es de rescatarlas con seguridad, rechazando la naturalización de la nueva normalidad. Finalmente se presenta a la herejía como práctica metodológica para el desempeño docente en ciencias sociales. Entendida aquella, como reflexibilidad de las estructuras y procesos sociales, prácticas y discursos, pensando y discutiendo lo ya naturalizado como normalizado.

Palabras clave: educación; ciudadanía; distanciamiento; biopolítica; Ciencias Sociales; herejía.

Abstract: The problem emerges as a counter of the diverse and complex virulent social processes triggered from the assumption of the current pandemic as consummated fact. Establishing policies, speeches, and practices in which the citizenship only allowed themselves to be carried away as in the course by a torrent, answering to the imposture only by reflection of it. Establishing the precedent, the door is opened to the recurrent invocation of the pandemic, and at 
the same time, in a paranoid way to another probable future virus, in a cyclical way, as a reminder and justification (legitimacy) to promote behavior (government) using a very specific theme. of health; however, spreading and affecting all areas of society. As objectives, the effects of knowledgepower, causes and consequences of the application of certain devices that simultaneously invade and normalize society as a whole and to each individual are made explicit. Just as, in the face of the normal fear of the majority of citizens in the face of the possibility of death, although this is objectively limited, as it will be seen, progress is made out of the proportion in the invasion of the social life, both private and collective, in an extension of actions of government beyond the strictly sanitary. Educational indicators playing a part in the exercise of citizenship and its civic empowerment have been considered, as a key of protection and guarantee of fundamental rights. Also, some numbers regarding the pandemic and mortality that allows to measure the disparity as well as what can be beyond the sanitary excuse for such an intensive government deployment. And, finally, a discussion of the object of study of the teaching exercise in social sciences, as the core of panic, interweaving the negative association between social relationships with the social spacing. The method has been qualitative, based on comparative documentary analysis. The results show how in a situation of health risk the opportunity is used politically and strategically from bio politics for an unprecedented expansion, depth, and acceleration in the application of strategies and tactics of social discipline more efficient and effective than those of the beginning of modernity. Necessaries, from the system, and for the development of the capital, so that the human being without property becomes a useful and docile worker, and at the same time 
politically consistent. This is what is called the construction of hegemony processes for the legitimate exercise of domination. The technologies of the self (Foucault, 1990) improve the internalization of the external social structures unconsciously in the context of late neoliberal modernity through the psycho-power, using the dataism and the illusion of freedom in the performance of the improve yourself. (Han, 2014a). Even the attempt to redefine the practice itself and the concept of key relationship of the social life, expressed in various ways as social spacing; when, what it is about here, is to rescue them safely, rejecting the getting used to the new normality. Finally, heresy is presented as a methodological practice for teaching performance in the social sciences. Perceived that one, as reflexivity of the social structures and processes, practices, and discourses, thinking and discussing what is already naturalized as 255 normalized.

Keywords: Education; citizenship; spacing; bio politics; Social Sciences; heresy. 


\section{Introducción: el contexto para educar y el ejercicio de la ciudadanía}

La tesis de partida que presupone el viaje de este artículo es que una población mayoritaria de ciudadanos, entendidos estos, exclusivamente en términos legales-constitucionales (concepto restringido), pero sin acceso intergeneracional a la educación y a la cultura, impide su desarrollo cognoscitivo en los tiempos pertinentes y necesarios; y con ello, condicionando ciertas prácticas sociales y tomas de decisión, en cuanto al conocimiento como a las formas de las mismas.

Esto, es posible de abordar desde varios lugares distintos, entre otros, desde los indicadores de analfabetismo absoluto-funcional, asimismo en su conexión con el conocimiento y habilidades digitales, emergente particularmente como problema con la crisis educativa actual en tiempos de pandemia, traduciéndose en desigualdades digitales o en la hegemonía del pensamiento concreto.

De esta manera, se puede pensar desde algunos cuerpos conceptuales, para deducir efectos o consecuencias desde algunos indicadores empíricos, considerando por ejemplo las cuatro etapas reconocidas por Piaget (1999) desde su epistemología genética como ajuste progresivo entre la maduración biológica y la preparación según el desarrollo de las distintas etapas; asimilación (conocimientos previos) y acomodación (conocimientos nuevos), y en su equilibrio. $Y$ así, de una serie de capacidades -leer, escribir, definir, comprensión lectora, etc.- que conduzcan a la competencia 
del ejercicio de la ciudadanía fruto de determinados procesos de enseñanza y aprendizaje (concepto amplio).

La ciudadanía empoderada presupone el ejercicio cívico, la asimilación del silencio a la palabra, a la acomodación a otra palabra distinta que piensa, que enuncia portando un concepto, a las acciones ahora con conocimiento; solo resta la coherencia de las mismas, según sus prácticas. Esto último presupone la elección libre y responsable de cada ciudadano, fundamento de la educación pública y la construcción de la ciudadanía política; y el límite de hasta dónde puede llegar la práctica docente. Ir más allá del mismo conllevaría a un viaje sin retorno, que oscilaría entre la parcialidad del lineamiento político y la imposición autoritaria.

257 Así, sea por la cantidad y/o calidad en el acceso a la educación y a la cultura por parte de la ciudadanía, por las tasas de analfabetismo absoluto, funcional, digital; la prevalencia de un pensamiento concreto en la mayoría de la población nacional, 0 por las condiciones contextuales situacionales a la experiencia vital de todos los implicados en el proceso educativo, y por tanto, de los sujetos-actores que constituyen la comunidad educativa. Provoca la discordancia entre formación y ejercicio de la ciudadanía, como un derecho que hay que garantizar y proteger (estado garantista).

¿Cómo educar para una formación integral intertransdisciplinar de ciudadanos críticos empoderados en un sistema educativo pensado y orientado principalmente para la formación profesional para crear capital humano? Así, para Han (2018): 
Las instituciones de educación superior producen futuros trabajadores. Los estudiantes se llaman clientes, y esperan de sus profesores una transmisión del conocimiento. La educación entendida como aumento del rendimiento caracteriza todo el sistema ¿Cómo se puede cuestionar una sociedad como ésta, que es el resultado de la colaboración de todos?

Ahora bien, ¿en qué contexto desenvuelve el educador su práctica docente y actividades más allá de la cátedra, la investigación y extensión, siendo ella/el mismo/a, al igual que el alumnado del nivel que se trate, productos de sus circunstancias sociales e históricas? Ante el avance de la sociedad del rendimiento (Han, 2012; 2014; 2014a; 2020a), sin poder siquiera comprender sus implicancias, y nuestra colaboración 'voluntaria' con su producción y ampliación, nos preguntamos: ¿Qué lecciones, aprendizajes y oportunidades se pueden problematizar a partir de la emergencia social en tiempos de pandemia para la labor educativa crítica y enfoque garantista (protección del derecho a la formación integral y al ejercicio ciudadano) por parte de los maestros y profesores de ciencias sociales en Paraguay respecto a su alumnado?

Así llevamos desde el año 2000, encarando la urgente tarea de destruir el modelo "europeo y humboldtiano" de la Universidad estatal para metamorfosearla según el modelo "anglosajón" de la Universidad privada. Así expresaba el asunto el documento del Círculo de Empresarios "Una Universidad al servicio de la 
sociedad", un documento de hace quince años. Por aquél entonces, había que implantar el Plan Bolonia, pese a que gran parte del profesorado y el noventa por ciento de los estudiantes se oponían a ello. Ahora bien, no era un futuro posible, era un destino. Bolonia fue como una apisonadora, no dejaba opción. La cosa había sido diseñada en las conversaciones sobre educación de la OMC y no admitía réplica... propone estrechar los vínculos entre las universidades y las empresas, y como siempre, flexibilizar aún más el tejido universitario para amoldarlo a los retos y desafíos que las voces de los mercados dicten desde las alturas. (Fernández Liria, 2020)

Ante esta perspectiva, más allá de la posible confusión y hasta solapamiento entre las variables intervinientes como el analfabetismo funcional, el digital en el dataísmo, y la hegemonía del pensamiento concreto, lo que importa es primero mostrar algunas de esas características del contexto que inviabilizan alcanzar (metas y objetivos) y por tanto, saber-hacer (aplicar) determinadas capacidades y competencias necesarias para la práctica del ejercicio del empoderamiento cívico de la ciudadanía.

7 de cada 10 paraguayos es analfabeto funcional, no entiende lo que lee. Y no sería extraño que un sector importante de universitarios termine una carrera universitaria sin leer un libro completo. Sólo un capítulo por aquí. Uno por allá. $Y$ se nota en el poco 
vocabulario que empleamos. Es gravísimo para la patria. (Martini, 2020)

Acompañando a Piaget (1999), si compartimos que el desarrollo cognoscitivo se da en cuatro grandes etapas, como fases en proceso: etapa sensoriomotora, etapa preoperacional, etapa de las operaciones concretas y etapa de las operaciones formales, cada una de las cuales representa la transición a una forma más compleja y abstracta de conocer. Entre el analfabetismo funcional, el digital, ligado fundamentalmente al primero y no solo a la herramienta e información en sí mismas y el pensamiento concreto, Paraguay muestra que es imposible aún contar con una ciudadanía empoderada. A no más que una opinión 'pública' difusa, fragmentada, fruto de formadores de opinión, y aun así, mínima, a través de herramientas como Twitter. Lejos todavía de hacer ciudadanía. Simplemente porque no puede serlo, pues no cuenta con el desarrollo de capacidades para ello y, por lo tanto, de ejercerla. $\mathrm{O}$ bien, tiene serias limitaciones como tal, y por tanto, lo que puede demandar, defender y proponer.

Al respecto puede leerse en el Plan Nacional de Educación 2024 (MEC, 2011, p. 55) $)^{2}$, que:

Asimismo el estudio internacional sobre educación cívica y ciudadanía (ICCS) 2009 realizado bajo la coordinación de la Asociación

\footnotetext{
${ }^{2}$ Lo mismo se dice en el documento Agenda Educativa 2013-2018 del MEC (https://www.mec.gov.py/cms/?ref=294506-agenda-educativa-2013-2018, p. 16). Asimismo, en la p. 15, bajo el subtítulo: El rendimiento académico en la educación paraguaya, puede leerse que: "Lo preocupante de estas cifras es que un segmento muy pequeño de los estudiantes garantizan aprendizajes de lecto-escritura y uso de números competencias fundamentales para el desempeño de las personas en la sociedad globalizada, durante su tránsito por el sistema escolar."
} 
Internacional del Logro Educativo (IEA -su sigla en inglés) revela la escasa preparación cívica y ciudadana de los/as estudiantes de nuestro país.

Puede apreciarse este panorama con estadísticas nacionales de cotejo en el documento titulado "Informe Nacional Analítico. Resultados de la primera evaluación censal de logros académicos a estudiantes de finales de ciclo y nivel del Sistema Nacional de Evaluación del Proceso Educativo" (SNEPE, 2019). Análisis descriptivo de las pruebas en las que participaron los estudiantes que culminaban cada uno de los tres ciclos que conforman la oferta de Educación Escolar Básica y el tercer curso de la Educación Media. El informe describe los resultados del rendimiento académico de los estudiantes en las pruebas

261 SNEPE 2015, así:

A pesar de las aparentes diferencias de rendimiento entre departamentos, la distribución de los estudiantes en función a sus niveles de desempeño prueba que la situación es relativamente crítica a nivel país, ya que 3 de cada 10 estudiantes obtuvo menos de 450 puntos en la prueba SNEPE; es decir, se encontraban en el nivel I de desempeño, lo que significa que su rendimiento fue insatisfactorio. Cuatro de estos 10 estudiantes se ubicaron en el nivel Il indicando que el aprendizaje de estos chicos debe mejorar, pues su rendimiento se ubicó entre 450 y 550 puntos. Dos de cada 10 estudiantes demostró niveles de conocimiento aceptables (nivel III) con puntajes entre 550 y 
650; mientras que solo un estudiante de cada 10 alcanzó el nivel IV, considerado como satisfactorio, con puntaje por encima de 650.

Coincidentes con este diagnóstico educativo, se presentan asimismo datos del Plan Nacional de Desarrollo Paraguay 2030 (2014), de la Secretaría Técnica de Planificación del Desarrollo Económico y Social. Así, respecto a la educación, se describe el Índice de Oportunidades Humanas $(\mathrm{IOH})^{3}$ como uno de los principales índices sociales de referencia internacional para la medición de los avances del país en el campo del desarrollo social. Resultando para la variable educación en un Bajo Nivel Educativo $\mathrm{IOH}$ del 74\% (2014, p. 30). Si se observa otro de dichos índices, tomando la variable Desempeño Escolar ${ }^{4}$, se coloca en el ranking con un $74 \%$ de $6^{\circ}$ grado con desempeño menor al nivel III (de IV), ubicándose así penúltimo en Sudamérica, solo Guyana presenta un índice más bajo. Lo cual se repite si se toma el Índice de Desarrollo Humano (IDH), con el lugar $111^{\circ}$ de 187 países. Asimismo, continúa el Plan (p. 31):

La eficiencia del sistema también se ve comprometida. De 100 que ingresan a la educación escolar básica, solo egresan 50 . En el nivel medio (15 a 17 años) el $70 \%$ de los que se matriculan llegan al egreso, pero del total que ingresa al 1er grado solamente 35 de cada

\footnotetext{
${ }^{3}$ El Índice de Oportunidades Humanas ( $\mathrm{IOH}$ ) busca medir las posibilidades de acceso de menores de 18 años a servicios considerados básicos para el desarrollo pleno de las capacidades de las personas, según sus circunstancias personales al nacer como ser lugar de nacimiento, nivel socioeconómico de los padres, etnicidad, o género.

${ }^{4}$ Resultados preliminares de la prueba SNEPE 2010. Dirección de Evaluación de la Calidad Educativa, MEC. Agosto 2011. Lo que se corresponde con los otros datos del SNEPE (2019) que describe datos al 2015.
} 
100 llegan a egresar del 3er curso de la educación media (12 años de escolaridad).

\section{El escenario de la pandemia y biopolítica}

En épocas de crisis, como la que se generó con la actual pandemia por la propagación del virus causante del COVID19 a nivel mundial, las sociedades exponen su historia a pesar de ellas mismas, sea de manera institucional como personal. Particularmente, de los sistemas de protección social pública vigentes que representan el desarrollo de su Estado Benefactor (Welfare State): que implica variables para el desarrollo de la calidad de vida, no simplemente no estar enfermo. Tanto en infraestructura y servicio sanitario, como en su integralidad con los de agua potable fluorada,

263 red cloacal, red eléctrica, comunicaciones, la seguridad laboral y alimentaria en tiempos de cesantía, seguro de paro, mesas de conciliación, etc., así como del acceso y calidad estructural e histórica estratégica a la de la educación y la cultura que marcan el comportamiento cívico de su población, retomando el concepto de salud como total, natural, psicológico y social.

Previendo la saturación-colapso de una estructura sanitaria débil, retrasada e ineficiente, y la deuda de inversión progresiva en el área, el discurso de los infectólogos pasa a dominar hegemónicamente como saber-poder legítimo para su instrumentalización política; expresión además de un reconocimiento excluyente, para la toma de decisiones gubernamentales de todo orden. Más allá del campo exclusivamente médico-biológico viral, en una extensión y profundidad sin precedentes de la biopolítica, invadiendo y 
explorando territorios de los derechos humanos, garantías sociales e individuales fundamentales.

Sin poder entrar aquí en el rédito económico que supone la pandemia para determinadas redes y círculos del poder político y sanitario en el país, que son expresión de la institucionalización de la corrupción en la relación de la salud pública y privada, con procesos de compras fraudulentas y licitaciones orekuete para insumos sanitarios sin control y fiscalización sistemática tanto de calidad, costos y transparencia. Y/o, en otras esferas de negocios en medio de la campaña del miedo para incentivar el consumo, subiendo precios, de productos de todo orden que además no tienen ninguna efectividad específica para prevenir o tratar el virus. (Parker-Pope, 2020)

Por eso, ante la actual pandemia, el Premio Nobel de Química, Michael Levitt (2020), critica a los médicos que acuden a los medios de comunicación para alarmar a la población:

El problema con los epidemiólogos es que sienten que su trabajo es asustar a la gente para que se encierre, para que se distancie socialmente. Así que dicen 'va a haber un millón de muertes', y cuando solo hay 25.000 dicen 'es bueno que hayan escuchado mi consejo'. Esto sucedió con el ébola y con la gripe aviar. Es solo parte de la locura".

Por su parte, para Agamben (2005), medidas "frenéticas, irracionales y absolutamente injustificadas" (estado de excepción, de alerta, confinamiento, etc.). Una cosa es el dominio de un saber-poder, y otra muy distinta, su uso y 
efectos, más allá del mismo. Siguiendo a Foucault (1980), quien cuando enumera las medidas a adoptar cuando se decretaba a partir del S. XVIII la peste en una ciudad, estableciéndose una sociedad disciplinar de control de la población con medidas restrictivas de la libertad de movimiento y el registro permanente justificados; así como su castigo o sanción, en la gravedad de la pandemia en base a una legitimidad sanitaria focal.

De esta forma, frente al avance en ámbitos y con medidas más allá de la legitimidad sanitaria, las libertades y derechos parecen delegarse y relegarse peligrosamente a un segundo plano de la propia vida. A Hajj (2020) le llama la atención cómo la gente ha sucumbido al pánico, aceptando el repliegue de la libertad aseguradas en derechos y garantías fundamentales no solo en Europa, sino en gran parte del 265 mundo.

Si tenemos en cuenta que los sistemas de control y vigilancia en los aeropuertos impuestos tras el 11 de septiembre de 2001 siguen vigentes, aunque parecían excepcionales en su momento, los efectos que puedan tener las tecnologías del control sobre la pandemia del coronavirus podrán prolongarse. La gente tiende a obedecer a los gobiernos en situaciones de peligro y las sociedades temerosas y cerradas en sí mismas son más fáciles de gobernar. ¿Por qué no iban a inventar los gobiernos peligros cuando ellos mismos han sido a lo largo de la historia el mayor peligro para la libertad humana, cuando no se les resiste de forma consciente? (Hajj, 2020) 
Parafraseándolo, las excepciones como la pandemia revisten de legitimidad al ejercicio de la biopolítica que la invoca, y es capaz de recrearla, para perpetuar su avance y efectos. En un escenario nuevo, que permite bajo la máscara de la legitimidad particular sanitaria, la aplicación sistemática discrecional de saberes y poderes a través de dispositivos (medios de comunicación, jurídicos, sanitarios, policiales, militares, educacionales, barriales, familiares, etc.) que conforman conductas, normalizándolas.

Al respecto, en palabras de Michael Levitt (2020) “... sostuvo que el daño social del confinamiento ha sido extremo." Así como el columnista de la nota, comenta que Levitt "... cree que con algunas recomendaciones puntuales, como usar máscaras desde el comienzo del brote y adoptar ciertas normas de distanciamiento social, se habría obtenido el mismo resultado en términos sanitarios, pero a un costo muy inferior." (Infobae, 2020)

Un objetivo central de este papel de trabajo es hacer explícita esta naturalización consecuente con los procesos ejecutados de normalización, que incluyen el control, la vigilancia, hasta ésta hacerse conducta inconsciente que sujeta al sujeto ahora sujetado. El sujeto se vigila a sí mismo, y entre sí (delación-pirahue), con una sensación de libertad individual atomizada y desvinculada que no es más que la participación en el panóptico del enjambre. (Foucault, 1980; 1987b; Han, 2014; 2014a)

Compartiendo esta perspectiva de la des-naturalización, abro a los colegas otras preguntas en la misma dirección: ¿Qué papel juegan en este escenario las ciencias sociales? Y más particularmente: ¿Cuál es nuestro lugar? ¿Qué se 
espera que desarrollemos como docentes e investigadores del área entre sujetos integrados o actores que participan empoderados como ciudadanos/as de manera conjunta con el alumnado de la problematización de nuestra vida cotidiana?

Acompaño posturas como la de Michael Levitt, quien proviniendo del campo de las ciencias naturales y duras, da un lugar central a que haya un debate abierto en torno a la pandemia y a las estrategias para enfrentarla, antes que asumir resignadamente su impostura con sus efectos diversos: "Me dijeron en numerosas ocasiones 'no eres epidemiólogo, cállate'. "Muchas cosas salieron mal, pero creo que lo principal es que solo necesitábamos pensar y discutir las cosas un poco". (2020) Que es la propuesta que atraviesa el espíritu de este papel de trabajo, practicar la 267 herejía como pensamiento crítico, fruto de la discusión y los mecanismos de prueba y validación; a contracorriente de lo normalizado, lo previamente social e histórico naturalizado.

Así, valga de aperitivo un diálogo ${ }^{5}$ no imaginario con (Disparador): "Esta pandemia ha demostrado con creces que este modelo de Estado ha fracasado, pero además refleja algo más crudamente perverso: que "queremos volver a esa normalidad" en las mismas condiciones en que estábamos y peor." (Haciendo referencia a los comentarios de la ciudadanía en las redes sociales respecto al orden social de Paraguay actual y antes de la Pandemia).

\footnotetext{
5 Diálogo transdisciplinar real on line entre colegas de las ciencias sociales intercambiando ideas en las redes sociales respecto a las medidas gubernamentales frente a la alarma internacional de riesgo de expansión del Covid 19 , en el contexto e historia de Paraguay; considerando asimismo las opiniones de la ciudadanía en general. Diálogo indiciario para este y otros artículos y ponencias. Compartir miradas y abordajes respecto al quehacer profesional en nuestra área. Por ello su lugar.
} 
(Respuesta): "No sé si quieren, si pueden hacerlo con sus capacidades actuales, herramientas disponibles, y nivel de aprendizaje alcanzando; tampoco sé en qué medida se dan o no cuenta. Tal vez no les estemos llegando o presentando nosotros mejor ese panorama, sin paternalismos, para que se formen y actúen críticamente en consonancia. Pedagógicamente qué herramientas deberíamos compartir para que cada uno emprenda su libertad según su arbitrio, ahora con conciencia y responsabilidad. Falta mucho mismo apreciado amigo y colega. El stronismo vacío el alma de la educación, la cultura, el pensar y actuar empoderadamente como ciudadanía crítica. Y adiviná? Se da la lógica de la regresión lineal, de lo único que se conoce en pensamiento y acción, de lo único que viene de un pasado todavía muy resiente y doloroso, mezcla de ignorancia y autoritarismo (Caballero, 2012). Muchas/os aplauden y le dan espacio al mburuvicha que homenajeó hasta de manera oficial y pública al Stroessner. Lamentable! Ojo, y no hay que quedarse allí, a partir de la crítica de los del otro lado, de los propios de siempre, de los integrados, me enfoco más en aquellos que habiendo tenido la oportunidad de formarse, y hasta de colegas de trabajo. Entonces: ¿Qué se le puede exigir, esperar o reclamar al pobre, excluido, ignorante, acostumbrado al autoritarismo?"

\section{Geometría y distanciamiento social: objeto de estudio como núcleo del pánico}

Las ciencias sociales han sido posible de desarrollar a partir que el hombre se establece a sí mismo como sujeto y objeto de problematización y conocimiento (Foucault, 1969). Así, con aportes de autores precursores, clásicos, y 
contemporáneos, ha sido posible construir un objeto de estudio que diera especificidad a las mismas, cada vez más particular; así como dotar de métodos y técnicas que garanticen la objetividad del abordaje y su carácter sistemático. Autores como Augusto Comte (dinámica y estática social) Karl Marx (relaciones de producción), Max Weber (acción y relación social), Emile Durkheim (hechos sociales), Georg Simmel (formas de socialización y el cruce de los círculos sociales), y el propio Talcott Parsons (interacción, estructura y función) son parte de una larga y prestigiosa lista de los fundadores del nuevo campo de estudio y sus reglas.

Coinciden sin embargo, en que todas las disciplinas sociales, de manera transdisciplinar, convergen en el territorio de la relación social, como concepto clave para los diversos abordajes de las ciencias sociales; reconociendo la superación del nominalismo sociológico, y, comprendiendo que el ser humano es producto de sus relaciones sociales y los diversos procesos de socialización que hacen a sus circunstancias vitales como ser social en desarrollo.

Ya Georg Simmel (1920), visionario de la constitución de la sociedad en el pasaje de la diada a la triada, así como de la conformación de la persona según el momento histórico en el que se producen diversos tipos de cruce de los círculos sociales. Su meta, una síntesis de las formas de socialización -tipos de relación social, independientes de los contenidos de las mismas. Haciendo una explicitación de la distancia social, el número de participantes, etc., dentro de una subteoría que denominó 'geometría social'. Haciéndolo un magnífico descriptor de la constitución de la sociedad y de la vida cotidiana a partir de los ámbitos y relaciones 
microsociales. Sin embargo, tanto la relación misma, como las formas en que pueden o no darse en tiempos de pandemia, y su propia conceptualización, se ponen en discusión o pasan en ambos planos a ser replanteadas.

Esto, según determinados dispositivos de saber-poder que responden a la práctica de la biopolítica que intenta definir una nueva normalidad. Poniendo en jaque tanto el cómo relacionarse, así como su conceptualización. La postura aquí es mantener la relación social como núcleo de socialización, y como concepto central de las ciencias sociales, como contramedida a las imposturas de la sociedad del rendimiento como expresión del teletrabajo, la mediación virtual en flujo on line, y el aislacionismo individual. Asociándola enunciativamente para naturalizarla como nueva normalidad, para que la gente se vaya acostumbrando, a la palabra y en sus implicancias u efectos.

Más allá del distanciamiento o formas de relacionarse con seguridad, la vida, es mucho más que eficiencia y eficacia productiva, que ya no separa su ámbito-espacio específico, pues todo lo invade, difuminando lo laboral, lo educativo, hasta lo recreacional con el espacio de lo íntimo, así como sus tiempos, unificándolos. Más que el mundo contemporáneo asociado al imperio del avance de la neotécnica, supremacía instrumental de las TICs y las formas de relacionamiento mediadas que todavía parcialmente implican. Si trasladado a la vida cotidiana se fetichiza la unidad de análisis asociada a los individuos, antigua, muy antigua aspiración liberal desde sus orígenes, que intenta romper el tipo de lazos y posibilidades de asociación que genera la relación social, clave de la construcción y cualquier intento de transformación social. 
Una cosa es el individuo, otra cosa, la relación social. La segunda es cualitativamente diferente a la simple suma nominal de individuos.

Consciente asimismo que una cosa es el distanciamiento social que impide, modifica o pospone las relaciones sociales ex ante pandemia, y que otra muy diferente es la distancia de seguridad para evitar contagiar o contagiarse. Así, se hace pertinente preguntar-se reflexivamente por qué la segunda implica o conlleva natural y necesaria de manera asociada en el lenguaje, en las órdenes, restricciones y en los controles, a la primera. Esta normalización opera como necesidad aun siendo falsa. Puedo relacionarme en la mayoría de los espacios e instancias de socialización hogares, plazas, calles, etc.- sin ningún riesgo para mí mismo y para terceros, conversar, y mantener relaciones

271 sociales a una distancia de seguridad, presuponiendo educación, cultura y civismo. De esta manera, se le dota de un blindaje, como diría Lakatos (1983), con un cinturón protector al objeto de estudio transdisciplinar de las ciencias sociales; al tiempo que la defensa de los derechos y garantías de los ciudadanos, en suma, de una práctica y concepto de libertad en riesgo. Que se ha hecho retroceder y arrinconarse, pero que resiste, lucha, denuncia y demanda su protección, claro está, desde nuestra profesión y asimismo como ciudadanas/os empoderados y participativos cívicamente.

Con la excusa de la pandemia se ha producido una fractura cívica basada en el acatamiento del aislamiento social impuesto, del confinamiento, del 'no ver a nadie', con el único consuelo, que esta vez, tal vez, lo sanitario lo requiera, y así auto engañarnos de manera cómplice con un concepto 
confuso de legitimidad, que consuela a nuestra psique en una 'renuncia voluntaria a la libertad'. Las autoridades hacen un llamado engañoso invocando la salud como bien público, paradójico en una sociedad capitalista, y más, con un incipiente Estado Benefactor. Pero: ¿cómo renunciar a relacionarnos, concepto que enuncia lo que nos hace humanos? Defender un estado garantista, medidas de protección social, la legitimidad, o su problematización en un estado de alerta o emergencia sanitaria, es asimismo luchar por mantener la libertad de las relaciones sociales. Para Michael Levitt (2020):

Los números se mueven de manera muy consistente cuando se miran todos los lugares que han sido muy afectados, particularmente en Europa. El número simbólico de muertes antes de que las cosas se detengan es de alrededor de un mes de muertes naturales, que es algo así como una entre mil.

Cuyo equipo analizó y dio seguimiento a los datos de 78 países con más de 50 casos de coronavirus reportados. Llegando a la conclusión preliminar de que la evolución de la pandemia sigue una tendencia independientemente de las medidas variadas que se hayan aplicado.

Es pertinente preguntar (se) por tanto, si: ¿El miedo y el clima de pánico que se ha generado, y su contraparte en medidas de control, vigilancia y aislamiento social son proporcionales al riesgo estadístico de mortalidad? Al respecto Han (2020b) muestra en su $8^{\text {a }}$ definición, que:

El pánico ante el virus es exagerado. La edad promedio de quienes mueren en Alemania por 
Covid-19 es 80 u 81 años y la esperanza media de vida es de 80,5 años. Lo que muestra nuestra reacción de pánico ante el virus es que algo anda mal en nuestra sociedad.

Mientras, en Paraguay, los datos del último reporte del Ministerio de Salud Pública y Bienestar Social, al 24 de mayo del 2020, respecto al impacto sanitario del COVID-19 en el país, los indicadores muestran: 862 personas confirmadas con coronavirus; 544 activos; 307 recuperados; y, 11 personas fallecidas. Por su parte, el Índice de fallecimientos por cada 100.000 habitantes es de 0,146.

La mayoría de las personas infectadas ha sufrido solo síntomas leves y se recupera (@MazzolleniJulio, 2020). La cifra de fallecidos se mantiene en once, sin mayores detalles 273 hasta ahora sobre el promedio por edades (Información Oficial Paraguay, WhatsApp +595 991 224785).

Claro está que cada infectado o muerte es motivo de pesar, y que las medidas han redundado en este benigno escenario, pero no todas. Los datos casi hablan por sí mismos, en un país con unos 7.122.661 habitantes, las medidas que afectan los derechos y libertades fundamentales, así como la manera en que se han ejecutado, van probadamente mucho más allá de una estrategia sanitaria; al menos en sus efectos e implicancias a darle seguimiento en su evolución a corto, mediano y largo plazo. En términos de aislamiento, separación e inmovilización ciudadana, baja participación reivindicativa, empoderamiento cívico y protección de derechos. En las redes mode on line, es donde más se expresan los ciudadanos, constituyendo una expresión del problema que 
se discute aquí, exclusión, atomización y separación de la ciudadanía, además de vigilada y bombardeada en el contexto digital del dataísmo de la modernidad tardía.

Sin embargo, al mismo tiempo, se tiene que: "el año 2019 nos mostró una vez más una triste e invariable realidad. En Paraguay, hombres y mujeres mueren por causas que se podían haber evitado con simples controles médicos, estudios, vacunas y buenos hábitos de prevención". (ABC Color, 2019)

Gráfico №1: Enfermedades que más matan en Paraguay: De qué mueren los paraguayos

ENFERMEDADES QUE MÁS MATAN EN PARAGUAY

\section{DE QUÉ MUEREN LOS PARAGUAYOS}

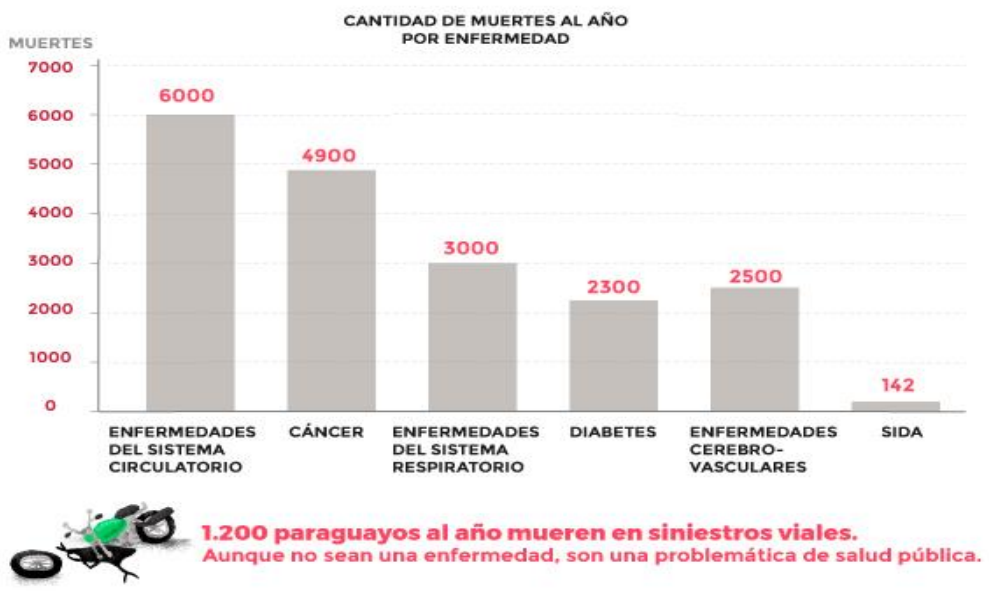

Fuente: ABC Color (2019). Anuario 2019. Las muertes que se pudieron prevenir.

Esta descripción de los efectos de la pandemia, si comparada con otras causales de mortalidad en el país, hacen que estas últimas sean mucho más significativas que 
aquellas. Por Enfermedades del Sistema Circulatorio (6000); Cáncer (4900); Del Sistema Respiratorio (3000); Diabetes (2300); Cerebro Vasculares (2500); SIDA (142) dando un subtotal de 18.842 personas fallecidas en el año 2019, más 1200 por Accidentes Viales. ¡Por Covid-19, 11! Sin embargo, sin implicar la puesta en marcha de toda esta parafernalia tanto de la biopolítica como mediática. La desproporción es notable respecto al abordaje de la salud de la población en una situación asumida como normalidad, naturalizándola cuando prevenibles -tanto por la población como por los profesionales de la salud-. Y, sin embargo, con un gasto y movilización de recursos casi incomparable ante la emergencia de la pandemia. En el decir de la columnista: "Paraguay, un país donde la gente no muere porque es inevitable, sino porque no se hizo lo suficiente para salvarla". (ABC Color, 2019). Entre contradicciones y paradojas, la sociedad disciplinaria y el biopoder se muestran, aun para el propio sistema del que forman parte, generalmente de manera impersonal e inconsciente. Como versa un grafiti o arte de calle, el virus es la propia sociedad capitalista. Uno y otro virus podrán sucederse, y así las prácticas de vigilancia y control.

Esto es claro, el problema sanitario existe, pero muchas de las medidas impuestas en la acción, y con un débil y confuso intento de legalidad que las legitime, no son proporcionales al problema en sí (formas de contagio y circulación) ni simétricas al conjunto de la población. Siguiendo al Premio Novel de Química, Michael Levitt (2020): "No hay duda de que se puede detener una epidemia con la cuarentena, pero es un arma muy desafilada y muy medieval. Podría haberse detenido con la misma eficacia con otras medidas sensatas". Mostrando el 
avance de recortes a la libertad, lo que se pone en riesgo, su peligrosidad, y la re-definición misma en la práctica de la vida cotidiana y de su conceptualización de la relación social, eje de nuestras disciplinas y de la vida social misma. ¿Son las medidas bajo estado de alerta o emergencia simétricas para todos los ciudadanos independientemente de su condición social? Pensemos en el costo económicolaboral, capacidad de ahorro, de consumo, de las exigencias sanitarias como uso de mascarillas, geles, guantes, etc., del confinamiento, y hasta de la propia movilidad.

Así, respecto a la asimetría social del riesgo y asimismo de las restricciones en sus implicancias, Han (2020b), en su $1^{\text {a }}$ definición respecto al COVID 19 expresa que:

El coronavirus está mostrando que la vulnerabilidad o mortalidad humanas no son democráticas, sino que dependen del estatus social. La muerte no es democrática. La Covid19 no ha cambiado nada al respecto. La muerte nunca ha sido democrática. La pandemia, en particular, pone de relieve los problemas sociales, los fallos y las diferencias de cada sociedad. Con la Covid-19 enferman y mueren los trabajadores pobres de origen inmigrante en las zonas periféricas de las grandes ciudades. Tienen que trabajar. El teletrabajo no se 10 pueden permitir los cuidadores, los trabajadores de las fábricas, los que limpian, las vendedoras o los que recogen la basura. Los ricos, por su parte, se mudan a sus casas en el campo. 
Las ciencias sociales ven a su objeto de estudio así problematizado, y las mismas se encuentran con la oportunidad histórica de ponerlo en discusión en las aulas, proyectos y publicaciones. Coincido con Hajj en que el distanciamiento social, sí infiltrado como nuevo archivo, dañará el concepto de ciudadanía, normalizando el significado de palabras ahora tan de moda como confinamiento, lo que significa vivir vigilado y con los derechos recortados.

Lo que lleva a temer "que el distanciamiento social al que ha obligado la pandemia se consolide como el modelo de las relaciones futuras, pues mermaría la capacidad compensatoria de conceptos como ciudadanía y democracia y facilitaría el ejercicio del poder a quienes estén mejor posicionados cuando el miedo se expanda". Hajj Saleh $277 \quad(2020)$

Adaptando a Wendy Brown (2015), la soberanía en declive no es tanto de los estados amurallados, sino la de los propios individuos; amurallados en su aislamiento social y confinamiento, fragmentados en términos de relacionamiento social y conectados fluidamente a través de la red. El sistema se transforma en parodia de la vida.

\section{Biopolítica: la sociedad disciplinar y el biopoder (bio y anátomo política)}

La temática que recorre todo el papel de trabajo es en definitiva el de la libertad. Si ya veníamos mal, la pandemia vino a oscurecer y distraer en su monólogo los diversos problemas de la sociedad capitalista contemporánea. Es 
más, como tesis, se presupone que la pandemia es el capital.

Ante ello, se echa mano a Harari (2020a), quien enuncia que "La epidemia es la tapadera perfecta para un golpe a las libertades". En la misma línea, se sigue a Hajj (2020), para quien: "Nada de esto es nuevo: todo precede a la crisis del coronavirus. De hecho, la crisis sanitaria mundial parece enmascarar con su fealdad un panorama ya de por sí muy desagradable."

A partir de allí, se incursiona en el desarrollo del biopoder, tan claramente desanudado por Foucault (1987b), y en su línea de pensamiento, mostrar que si bien, el escenario de la pandemia es sui generis, no significa más que una extensión y profundización acelerada del ejercicio de control a través de la bio y anátomo política, considerando otros contextos, recursos tecnológicos; así como la entrada en escena del poder bajo la piel, y al psicopoder, que se abordarán en el siguiente apartado.

Considerando el concepto de sociedad disciplinar o panóptica (Foucault, 1969; 1974; 1980), vemos que esta encuentra un campo fértil para su desarrollo contemporáneo a través de la oportunidad de la pandemia. Utilizando la naturalización del discurso médico como verdad y legitimidad. Explosión exponencial de control y vigilancia más que del propio virus. Y a través de diversos dispositivos de saber-poder, conducir gobernando conductas, acompañándolas (vigilancia, control, medición, etc.), enunciándolas (saber jurídico y médico); por lo tanto, produciéndolas de determinada manera. Acciones de control sobre acciones en dispersión, como consecuencias, y a su 
vez, como causas en el ejercicio de las mismas. La nueva normalidad se impone así a domicilio (confinamiento y aislamiento social), en las calles (movilidad y reunión), en los supermercados (distanciamiento, higiene, turnos), y en todos los ámbitos de la vida. Así, según Saleh (2020):

La Covid 19 no es la causa de la crisis, sino el elemento que la ha puesto de manifiesto. El mundo se ha mostrado, especialmente en los países ricos y poderosos, incapaz de lidiar con una crisis sanitaria que no es lo más peligroso a lo que se enfrenta el mundo. Los problemas relacionados con el clima y el racismo son mucho más peligrosos y ambos nacen de la estructura económico-política mundial de los países más ricos y fuertes, que se revelan hoy como los más conservadores y reacios al cambio, aunque ello conlleve más riesgos para la Humanidad y la vida.

Las ciencias sociales pasan a ocupar un lugar disciplinar sustancial, traspasando así los tres ejes de saber-podermoral. Se lo demanda el poder, siguiendo el paso, corriendo detrás, pasando primeramente por un período de abstinencia normativa, desorientado, todavía no enunciable. Causa y consecuencia en lo que debe ajustarse progresivamente a una serie de nuevos mandatos disciplinares (corsés), tensionando la legitimidad entre los derechos individuales $\mathrm{y} / \mathrm{o}$ colectivos hasta entonces sancionados, ahora en un campo diferente que se diseña en la marcha (Bourdieu y Passerón, 1981; Bourdieu, 1983; 1991b; 1993).

Produciendo ad hoc nuevas 'garantías' legales que den soporte de legitimidad a las acciones de gobierno, entendido 
este como conducir conductas de la población en general y de los individuos en particular, hasta en el más mínimo detalle. Ahora, encauzadas por decreto, normalizadas, vigiladas, exigidas. Entre miedos y restricciones, controles represivos, abusos, y ajustes de la legitimidad a la carta, las libertades y derechos parecen delegarse peligrosamente, y relegarse a un segundo plano de la propia vida: "El coronavirus es un permiso de supresión de todas las libertades que a título de protección se extiende sin derecho a réplica, ni cuestionamiento" (Galindo, 2020). De esta manera, la legitimidad se relaja, en el sentido que si las acciones del gobierno no tienen legitimidad jurídica, hay que producirla de alguna manera formal (enunciación).

Ahora bien, no existe lectura o interpretación posible de cualquier hecho, dato, o situación al margen de cualquier orientación, conceptualización previa, y así mismo de propuestas de intervención y desarrollo. De esta manera, puede comprenderse que no pueda entenderse que el discurso de las ciencias sociales como exentas de constituirse como expresión de un orden social histórico en particular y prácticas desde algún lugar con presupuestos e intereses.

Lo importante es que las prácticas, discursivas y no discursivas, siempre son productivas (positivas), fruto del ejercicio de relaciones de saber-poder, en su juego permanente en la dinámica fuerza-resistencia de las acciones, normas que hacen, imponen, invaden, abriendo nuevos espacios, caminos, controles, permitiendo y siguiendo, acompañando las nuevas prácticas. 
Para el caso específico del coronavirus, que implica a la salud pública, la medicina, etc., parafraseando a Foucault (1987a), la demografía es la disciplina junto con aquellas ciencias que dentro de un dominio abordarán las cuestiones acerca del biopoder y la anatomopolítica (Caballero, 2014). Constituyendo la natalidad, mortalidad y las migraciones los objetos específicos de la biopolítica en su análisis e intervención (Foucault, M., 1987a).

En esta línea de investigación más contemporánea y crítica, se incorpora la micropolítica, menos estructural, más pertinente a la dinámica de las relaciones sociales. Procesos todos, que hacen estratégicamente a la dinámica poblacional. Foucault ya enunciaba teóricamente la sexualidad (1987a; 1987b; 1987c), la locura (1987d), y la vigilancia y el castigo (1980), destacándolos como ejes 281 particularmente 'densos' que permitían su instrumentalidad para el desarrollo del ejercicio del poder (1974; 1988a; 1988b; 1990; 1993).

Tecnologías, dispositivos y prácticas que se modulan para: la reticulación del Espacio/Tiempo (cuarentena, ganar tiempo); Premios/Castigos (multas, código penal, prisión, toque de queda, restricciones, estado de emergencia); y, Mediciones/Examen (distancias, circulación, salvo conductos, movimientos, restricciones, uso de guantes, gel, mascarillas). Estrategias centrales a la hora de vigilar y de castigar, donde la verdad y sus formas jurídicas (Foucault, 1986) se instituyen pero también se adaptan, mutan, escribiéndose donde antes había un vacío.

El terror inducido va más allá del virus, pero asociado al mismo, también con el trabajo 24 hs al día sin tregua, sin 
pausa, ni otro tema por parte de los 'Mass Media', las redes sociales, la familia o el vecindario. La vigilancia, el control, la represión, entre cuarentenas en cuarteles y albergues, cierre de fronteras, estado de emergencia, multas, el accionar de la Fiscalía, imputaciones y la prisión. Simultáneamente en la nueva vida cotidiana auto-encerramiento, mantener distancias, movilidad limitada, cómo usar guantes y mascarillas 'correctamente'. Hasta volver a enseñarnos repetitivamente hasta cómo lavarnos las manos y desinfectar todo, a pesar de que ello sea una tarea imposible, y basado en el sentido común y no en la ciencia (Parker-Pope, 2020).

Mirar por encima del hombro si alguien nos sigue o nos ve, o si un vecino nos ausculta (delación-pyrague), hasta llegar a una barrera policial y ser perseguido y recibir disparos sin más. Linces, militares, policías, armas, con despliegue de excesos de todo tipo, en nombre de una 'guerra' para enfrentar un virus, siguiendo a un 'capitán', yendo mucho más allá (coimas, torturas, peaje a cambio de favores, barreras ilegales y gatillo fácil). Es la sociedad panóptica de modelo, todo se vale, el ejercicio lo es todo, y casi un éxito. Al menos haciendo internalizar conductas y colaborando en los procesos de su nuevo encauzamiento; una vez más, estoica y pasivamente, con la aceptación fatalista de la legitimidad del gobierno y su biopolítica.

Los derechos, garantías y protección social pasan a ser artilugios accesorios. En otras palabras, en el decir de Galindo (2020): "No poder respirar es a lo que nos condena el coronavirus, más que por la enfermedad por la reclusión, la prohibición y la obediencia." Bajo una aceptación 
legitimada en el terror, se posibilita que invasivamente se refuerce un régimen de vigilancia más eficiente y eficaz.

\section{Del vigilar y castigar al biopoder bajo la piel y el panoptismo digital}

Se discrepa con Harari en que es muy temprano el poder afirmar que se esté inaugurando una nueva época histórica. Sino más bien, que lo que ocurre, es una mutación de las tecnologías del poder en su desarrollo contemporáneo. Entre las cuales se encuentran la vigilancia masiva-personal biomédica (brazalete) y la geo-localización de datos en los móviles. Planteo que suele confundirse con el del enjambre digital propuesto por Han (2014). Solo que este último, aunque fundamente muchas de sus ideas en Foucault, 283 busca diferenciarse de él para lograr un lugar propio diferente en los aportes desde su propuesta filosófica. Dejando atrás la época biopolítica y entrando a la psicopolítica digital donde el poder interviene en los procesos psicológicos inconscientes.

Así, las palabras de Harari (2020a) apuntan más bien al biocontrol en esa transición dramática de vigilancia de 'sobre la piel' a 'bajo la piel'. Que podría llegar en un futuro demasiado próximo, en otra transición del rastreo interno global y al mismo tiempo individual, a la implantación 'voluntaria' de chips subcutáneos; bajo la legitimidad del saber-poder biológico-médico, acumulando las medidas antiterroristas 'pos september eleven'. Las implicancias respecto al impacto en las formas, cómo, dónde y con quiénes nos relacionamos, y en las libertades y garantías 
fundamentales, constituye una contradicción pragmática (Harari, 2020a):

En un momento dado, la epidemia acaba, pero el gobierno dice que es posible, que venga una segunda oleada, o que el brazalete también es muy útil durante la temporada de gripe. Que mejor hay que seguir llevándolo. Ese es el peligro.

Mientras, para Han (2014, pp. 84-85) empresas privadas como Facebook, Google y sirviéndose del Big Data operan como servicios secretos que vigilan nuestros intereses para extraer beneficio de nuestros comportamientos en internet y las redes sociales (dataísmo). El psicopoder, práctica disciplinar que no es nueva, es para Han más eficiente que el biopoder por cuanto vigila, controla y mueve a la población desde dentro. Problematizando de qué modo la revolución digital, internet y las redes sociales ha transformado la esencia misma de la sociedad, formando una nueva masa de individuos aislados, que carece de un nosotros capaz de una acción común, o de manifestarse en una voz. Lo cual impide la formación de un contrapoder que cuestione el orden establecido, adquiriendo éste rasgos totalitarios.

Citando al teórico de los medios Marshalll McLuhan (1964 apud 2014, p. 6), quien advertía acerca de las consecuencias imprevistas del desarrollo disruptivo del medio electrónico: "La tecnología eléctrica ya está dentro de nuestros muros estamos embotados, sordos, ciegos y mudos ante su encuentro con la tecnología de Gutenberg". Para, a partir de allí, realizar una analogía contemporánea con las consecuencias y efectos con la diseminación del 
medio digital que nos desborda con su flujo incesante de datos, dirá que:

Somos programados de nuevo a través de este medio reciente, sin que captemos por entero el cambio radical de paradigma. Cojeamos tras el medio digital, que, por debajo de la decisión consciente, cambia definitivamente nuestra conducta, nuestra percepción, nuestra sensación, nuestro pensamiento, nuestra convivencia. Nos embriagamos hoy con el medio digital, sin que podamos valorar por completo las consecuencias de esta embriaguez. Esta ceguera y la simultánea obnubilación constituyen la crisis actual. (Han, p. 6)

Las relaciones de poder continúan existiendo, siempre bajo otras formas, las libertades y derechos en los márgenes. El lugar de las ciencias sociales se hace así central. La sociología, de manera transdisciplinar respecto a su objeto, es un recurso sistemático, que junto a y con otros, parafraseando a Bourdieu (1983; 1993; Bourdieu y Passerón, 1981), consigue explicitar, tomar conciencia de los procesos de internalización de las estructuras sociales externas. La socialización siempre ha sido la manera legítima de construcción y desarrollo de capacidades negativas de autocontrol, vigilancia y disciplina en la conformación y direccionamiento de conductas, frutos de procesos políticos que varían las formas de las tecnologías del yo (Foucault, 1990). 
Se les debe recordar a Han y Harari que esos procesos, las prácticas sociales, devienen en conductas, acciones, comportamientos que, si bien son externos, son resultado de aquella previa internalización. El recurso de Harari de la transición de la biopolítica de 'sobre la piel' a 'bajo la piel' legitimada a través de las disciplinas morales-sanitarias o biomédicas (geolocalización, brazalete electrónico, seguimiento por Apps en dispositivos móviles). Y el de Han, a la psicopolítica digital como procesos psicológicos inconscientes; pretenden alejarse de la misma concepción para inaugurar una biopolítica diferente, otro paradigma, cuando en realidad, introducen una mutación contextual de la misma, una centrada en recursos tecnológicos del biopoder como para Harari (bajo la piel); y, para el caso de Han, un análisis fuertemente 'conectado' con algunos ejemplos asociados más al primer mundo donde se centra en la despersonalización a través del psicopoder en la era del big data (dataísmo). Sea vinculando la psicopolítica con la neotécnica, donde la tecnología se muestra no neutral y la tecnopolítica a manera de panóptico digital que narcotiza y conduce al enjambre (Han); o la transición dramática anteriormente descripta según la perspectiva de Harari.

Chomsky, Foucault, Hajj, Han, y Harari, entre otros pensadores de finales del siglo $X X$ e inicios del $X X I$, coinciden en asumir una posición crítica frente a los efectos de la sociedad capitalista tardo-moderna en su fase neoliberal ${ }^{6}$. De resistencia con grados variables de

\footnotetext{
${ }^{6}$ Como textos situacionales se recomienda leer las obras de Zygmunt Bauman, Modernidad líquida. Buenos Aires: Fondo de Cultura Económica. (1999); de Gilles Lipovetsky, La era del vacío: ensayo sobre el individualismo contemporáneo, Ed. Anagrama. (1986); y, de Jean François Lyotard, La Condición Posmoderna. Barcelona: Cátedra (1979). Como referentes entre otras obras y autores de una generación crítica europea de la $2^{\mathrm{a}}$ mitad del siglo XX que inaugura la problematización post, junto con otros aportes de variadas disciplinas y autorías.
} 
optimismo o escepticismo, acerca del avance del panoptismo basado en la biopolítica y en el panoptismo digital (dataísmo) como programación inconsciente y dominio del flujo de datos (Big data) que aturde bajo el acceso al psicopoder.

Nos dice Han (2018):

Al final de su libro El orden de las cosas, Foucault escribió que el ser humano desaparecería como una cara dibujada en la arena de la playa. Esta imagen es demasiado romántica. No será el mar lo que nos borrará, sino un mar de datos.

Es la distopia 'prevista' por Aldous Huxley con su libro Un Mundo Feliz. Sistema de dominación que en lugar de 287 emplear el poder opresor, utiliza un smart power, que consigue que los hombres se sometan (sujección) por sí mismos al sistema de dominación. El sujeto sometido no es consciente de su sometimiento (subjetivación). La eficacia del psicopoder radica en que el individuo se cree libre, cuando en realidad el sistema lo explota con una inducción falsa de libertad.

La gran diferencia entre internet y la sociedad disciplinaria es que en esta última la represión se experimentaba. Hoy, en cambio, sin que seamos conscientes somos dirigidos $y$ controlados. Las personas de 1.984 sufren, son torturadas; hoy hacemos clic y ponemos like. (Han, 2018).

Producto de la reificación del liberalismo individualista hedonista ante la crisis de la modernidad. 
Posibilitando conducir conductas, previéndolas, al detectar patrones de comportamiento y consumo del inconsciente colectivo que se expresan a través de la hipercomunicación, en un control y vigilancia total, ilimitado a través del accesoconexión al flujo de datos en las redes en distintos dispositivos y aplicaciones; lo que puede desembocar en una auténtica crisis de la libertad. (Han, 2014a).

Reclama por tanto, el ejercicio de la herejía, entendida esta, como elección libre frente a la coacción de la conformidad, que tiene el valor de desviarse de la ortodoxia, de la buena conciencia, de la conciencia tranquila y lo políticamente correcto. Figura de la resistencia contra la violencia del consenso, y admitirnos en lo que somos a través del silencio (ruido del zumbido del enjambre) y la contemplación (Han, 2014a). La filosofía y las ciencias sociales un refugio.

\section{Entre el miedo y la pulsión de vida: la legitimidad de derechos y libertades}

Las estrategias disciplinatorias en despliegue conllevan a una serie de situaciones, tales como la conducción de conductas, la trazabilidad de la previsibilidad de las mismas, en una lucha agónica permanente con los derechos y libertades, que pasan a cada instante a ser redefinidas, resemantizadas, rigidez-excepcionalidad, obediencia a la autoridad, fuga de prácticas de y por la libertad, que resisten, luchan crean e inventan.

Conducir conductas en fuga en tiempos de pandemia con cuestiones reales-objetivas sanitarias y otras con el pensamiento del miedo normal y el exacerbado, que 
encuentran el sentido común bajo cualquiera de sus modalidades, su refugio y aceptación de legitimidad. (Parker-Pope, 2020; Levitt, 2020; Caballero, 2012) Dónde termina la ciencia, dónde comienzan y bajo qué formas las prácticas disciplinatorias, el ejercicio del saber poder sanitario, moral difuso y con el ciudadano a disposición.

En cada medida y reglamentación: ¿Cuáles son sus bases, su legitimidad, sus límites, sus avasallamientos del individuo y de la sociedad, yendo más allá de lo estrictamente sanitario, extralimitándose, induciendo caminos? Se trata de ponderar críticamente la relación crítica entre el gobierno y su intento permanente e inexorable de conducir conductas, sus límites y márgenes, de los derechos, garantías, libertades de los ciudadanos.

El monitoreo central y los castigos duros no son los únicos métodos para lograr que la gente cumpla con lineamientos en su beneficio... Una población bien informada y auto-motivada, usualmente es más poderosa y efectiva que un pueblo ignorante vigilado por la policía. (Harari, 2020)

Las ciencias sociales y particularmente la educación se constituyen así en un espacio privilegiado para discutir los límites e implicancias de dicho control, de los dispositivos y de la disciplinización de la vida. De los abusos y avasallamientos de los derechos humanos, de la privacidad, derechos fundamentales e individuales, y también comunitarios, que permiten la problematización acerca de las medidas tomadas, desde el ámbito de la toma de decisiones, de las acciones desde los aparatos represivos (policial y militar), y los instrumentos legales al efecto, sus 
formas jurídicas, considerando hasta los límites constitucionales. Siendo el intento de implementar un régimen de vigilancia digital que al mismo tiempo normaliza (Harari, 2020; Han, 2020; 2020a; ABC Color Nacionales, 2020) dentro de un estado de alarma o emergencia por tiempo indefinido o cíclico, de acuerdo a decretos de ley, y el consiguiente avance autoritario, una actualización del programa disciplinar en desarrollo desanudado por Foucault (1980).

La tríada en espiral domesticación de los cuerpos, utilidad económica y docilización política continúa, ajustándose a los juegos de poder en la sociedad paraguaya contemporánea. La impersonalidad de los dispositivos y las prácticas como mecanismos de saber-poder no responden a cualquier tipo de voluntad individual, diseminándose y extendiendo sus normas del buen encauzamiento.

Produciendo nuevas formas de control, hasta la aceptación trágica del auto encierro y la vigilancia hacia dentro -en el vecindario, edificios, familias-, dando un paso más hacia una pérdida de libertad cualitativa significativa, entregando espacios fundamentales de la misma. El control se extiende y profundiza, lo que es más grave, 'delegando' en su introyección, la capacidad monopólica punitiva de las instituciones represivas y jurídicas del estado, a los sujetos de su acción, la propia ciudadanía. Qué mejor que se controle a sí misma, y entre ellos/as, a su interior. La coerción del control se siente y percibe menos al lograr el consenso de su auto imposición. Así, frente a la pregunta:

P: La necesidad de controlar la pandemia ha facilitado la aplicación de nuevas tecnologías que permiten un mayor 
control social de los ciudadanos. ¿Están en peligro la democracia y los derechos individuales? Se coincide con la respuesta dada por Hajj (2020):

Claro. Si tenemos en cuenta que los sistemas de control y vigilancia en los aeropuertos impuestos tras el 11 de septiembre de 2001 siguen vigentes, aunque parecían excepcionales en su momento, los efectos que puedan tener las tecnologías del control sobre la pandemia del coronavirus podrán prolongarse. La gente tiende a obedecer a los gobiernos en situaciones de peligro $y$ las sociedades temerosas y cerradas en sí mismas son más fáciles de gobernar. ¿Por qué no iban a inventar los gobiernos peligros cuando ellos mismos han sido a lo largo de la historia el mayor peligro para la libertad humana, cuando no se les resiste de forma consciente?

Desbordados y aturdidos, con una biopolítica más eficiente y eficaz, que se extiende, profundiza y renueva, desde estrategias de vigilancia, control y castigo interiorizadas desde afuera (sociales) hacia dentro (psicológicas y bajo la piel). Que incluyen la modalidad tecnológica de la internalización psicopolítica digital a modo de sociedad del enjambre y del cansancio (Han, 2014a), sociedad del ruido y el vacío, y hasta las literalmente 'bajo la piel' (biológicasdigitales; Harari, 2020; 2020a).

En años recientes tanto gobiernos como corporaciones han usado tecnología aún más sofisticada para rastrear, monitorear y manipular personas. Pero si no somos 
cuidadosos, la epidemia tal vez marque una importante mancha en la historia de la vigilancia. No solo porque puede normalizar el uso de herramientas de vigilancia masiva en países que hasta ahora la han rechazado, también porque significa una transición dramática de vigilancia de 'sobre la piel' a 'bajo la piel'. (Harari, 2020).

La separación y aislamiento social de los sujetos-actores expresa niveles nunca antes alcanzados de alienación bajo el disfraz de la comunidad virtual de la conectividad y la instantaneidad. Envés de la calle y plazas, la convocatoria de las abejas se dan a través de y en las redes, ateniendo reuniones, encuentros, foros, etc., virtuales y midiendo su impacto, segundo algoritmos que sintetizan el flujo de red y los me gusta. Llegando incluso hasta el sexo virtual.

En un recordatorio permanente de muerte, instaurando el miedo y la paranoia, instaurando la normalización de lo que es la nueva vida, y la vida misma pos pandemia naturalizada, des-historizándola. Los espacios públicos de relacionamiento y encuentro, libertades y derechos, pasan bajo la amenaza intermitente-cíclica viral-amenaza u enemigo externo, al ejercicio a distancia, conectados en la modalidad on line, y en su atomización, a la fragmentaciónsegmentación social en el discurso y en la práctica despolitizándolas. De esta manera, la biopolítica desarticula, en la constitución del nuevo orden social, la posibilidad de contestación, resistencia o transformación, a no ser que sea sistémica, y fluya. 


\section{El ejercicio de la docencia entre el hereje y el enjambre: del tú puedes al tú elijes}

¡Claro que se puede salir, relacionarse y no distanciarse socialmente con seguridad! La cultura política y el sentido común conceden espacios a la naturalización de la "nueva normalidad" desde la beta de la pobreza autoritaria y las condiciones de acceso a la educación. (Parker-Pope, 2020; Levitt, 2020; Caballero, 2012)

Cada cual sabe lo que hace y defiende en la práctica más allá de su discurso. Creo que, a pesar de todo, la mayoría de la población irá retornando la normalidad de sus vidas sin enterarse siquiera del síndrome de la cabaña. Otro intento desde la psicología comportamental en contribuir a las normas de buen encauzamiento de las conductas, como 293 tecnología de la biopolítica.

Sin embargo, espero que a muchos les sea posible defender y ampliar sus derechos y libertades con un optimismo informado según educación y cultura cívica. Y con una práctica acorde con ello, en todos los órdenes de la vida, que implica muchos aspectos y vínculos más allá de lo estrictamente sanitario. La libertad, su ejercicio, los derechos y sus garantías, se hacen más relevantes que la protección respecto a un virus; la forma en qué se desarrolle hablará mucho de la sociedad futura que estamos construyendo hoy.

Sustituyendo, tal vez más pertinente, abriendo el ámbito de la Filosofía al de las Ciencias Sociales (Han, 2014a, pp. 119127): 
Es una función de la $(s)$ ciencias sociales representar el papel de idiota. Desde un comienzo, la $(s)$ ciencias sociales está muy unida al idiotismo. Todo cientista social que genera un nuevo idioma, una nueva lengua, un nuevo pensamiento, habrá sido necesariamente un idiota. Solo el idiota tiene acceso a lo totalmente otro. El idiotismo descubre al pensamiento un campo inmanente de acontecimientos y singularidades que escapa a toda subjetivización y psicologización. (Los cambios en cursivas son míos).

El idiota, el loco y su locura como contracara de la sinrazón (Foucault, 1987a), como hereje moderno (Han, 2014a) se distingue por su singularidad, no como individuo o como persona. Su natura está dada no por cualidades personales, sino el contrapoder impersonal que brinda el estar desligado, desconectado, desinformado, excluido o por fuera de la norma que define la total conexión en red y la comunicación, como terminal de flujo de datos. Es como estar perdido, y no tener referencia alguna, haciendo camino al andar. La otra opción, que es la que se plantea aquí es resultante propositalmente politizado, educado, no formado exclusivamente para el capital y el consumo. Lo que permite por tanto la des-subjetivización y la des-psicologización, en cuanto socialización y bio-psico-política, abriendo caminos a la elección libre, al menos consciente y crítica.

El lugar de las ciencias sociales se hace así político y estratégico, como el de sus actores-docentes, investigadores, escritores, comunidad educativa-, a los que provocamos su locura como des-educadores para 
desarrollar la capacidad del pensamiento crítico-herético a través de la investigación por caminos distintos. "Creo que el verdadero virus fue el virus del pánico. Por razones que no me quedan claras, creo que los líderes entraron en pánico y la gente entró también, y creo que hubo una gran falta de discusión". (Levitt, 2020)

Por lo tanto, este artículo pretende propiciar ese pensar y debatir como herejía, como reflexibilidad epistemológica que a modo de contrapoder permita superar los obstáculos ya descriptos por Bachellard (1987). El más de lo mismo, del es lo que hay, simple naturalización de lo que se instala, y partir de allí se sigue y sigue aceptando a críticamente su impostura como hecho ya monótono, dado, normalizado. Saltando a otro canal, a otro flujo, haciendo posible el desarrollo de la capacidad de un aprehender diverso y una

295 cultura científica renovada, permanentemente asediada, y con ellas, la competencia plena del ejercicio de una ciudadanía libre.

\section{Referencias}

- $\quad A B C$ Color. 2019. Las muertes que se pudieron prevenir. (16 de diciembre de 2019). Por Estefhany Cantiè. Recuperado el 25 de mayo de 2020, de ABC Color: https://www.abc.com.py/especiales/anuario-

2019/2019/12/16/paraguay-el-pais-donde-se-muere-sin-que-seanecesario/

- ABC Color. 2020. Ciudadanos no facilitan datos a la app porque no confían en el estado dice TEDIC. Recuperado el 09 de abril de 2020 , de https://www.abc.com.py/nacionales/2020/04/09/ciudadanos-no- 
facilitan-datos-a-la-app-porque-no-confian-en-el-estado-dicetedic/

- Agamben, G.; Deleuze, G.; y Pardo, J. 2005. Bartleby, el escribiente. Valencia: Pre-Textos.

- Bachelard, G. 1987. La formación del espíritu científico. México: Editorial Siglo XXI.

- Brown, W. 2015. Estados Amurallados, soberanía en declive. Barcelona: Herder.

- Bourdieu, P. 1983. Cuestiones de Sociología. Rio de Janeiro: Editora Marco Zero.

1991. La Distinción. Criterio y bases sociales del gusto. Madrid: Taurus.

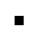
1993. El Oficio del Sociólogo. Buenos Aires: Siglo $\mathrm{XXI}$.

- Bourdieu, P., \& Passerón, J. C. 1981. La reproducción. Barcelona: Editorial Laia.

- Caballero Merlo, J.N. 2012. "La pobreza de la anarquía autoritaria. Rastros socio-antropológicos del zoon politikon", en e@@tina. Revista electrónica de Estudios Latinoamericanos. e।@tina, Vol. 10, núm. 39, Buenos Aires, abril-junio de 2012, pp. 35-54, http://www.iealc.sociales.uba.ar/publcaciones/elatina. 31 de mayo de 2020.

- Caballero Merlo, J. N. 2014. El recurso a la Epistemé foucaultiana: del discurso del saber al dispositivo de poder como práctica. En: Caballero, J. \& Peris, C. Sociodata.org. Paraguay desde la perspectiva de Michel Foucault. Sociodata.org. Asunción: Arandurá.

- Chomsky, N. 2020. Esto dice Noam Chomsky sobre el coronavirus y la geopolítica mundial. (CiudadValencia, Entrevistador) Valencia. Recuperado el 21 de marzo de 2020, de http://ciudadvalencia.com.ve/noam-chomsky-coronavirus-y-lageopolitica-mundial/

- Foucault, M. 1969. Las palabras y las cosas. D.F.,México: Siglo Veintiuno.

Editorial Graal.

1974. Microfísica del poder. Rio de Janeiro: 
. 1979. La arqueología del saber. D.F., México: Siglo

$\mathrm{XXI}$.

D.F., México: Siglo XXI.

México: Editorial Gedisa .

$\cdot$ 1987a. A história da Loucura. São Paulo: Editorial Perspectiva.

saber. D.F., México: Siglo Veintiuno.

placeres. D.F., México: Siglo Veintiuno.

1987c. Historia de la Sexualidad 2: el uso de los . 1987d. Historia de la Sexualidad 3: la inquietud de sí. D.F., México: Siglo Veintiuno.

Sociología, 2(3), 3-20. 1988a. El sujeto y el poder. Revista Mexicana de 1988b. Un diálogo sobre el poder y otras conversaciones. Madrid: Editorial Alianza.

Barcelona: Paidós. . (1990). Tecnologías del Yo y otros textos aines.

Almagesto.

. (1993). Las redes del poder. Buenos Aires: Editorial

- Galindo, G. 2020. Desobediencia, por tu culpa voy a sobrevivir. (Mujeres Creando. Texto publicado originalmente en Radio Deseo y cedido por María Galindo para \#Apocaelipsis). Recuperado el 08 de abril de 2020, de https://lavoragine.net/desobediencia-por-tu-culpa-voy-asobrevivir/

- Han, B-C. 2020. La emergencia viral y el mundo del mañana. Editorial: El virus no vencerá al capitalismo. (A. Gómez Bravo, Ed.) Recuperado el 24 de marzo de 2020, de Latercera.com: https://www.latercera.com/culto/2020/03/23/byung-chul-zizekcoronavirus-capitalismo/

- 2020b. 9 definiciones sobre la pandemia de ByungChul Han, el filósofo surcoreano que seduce al mundo. Recuperado el 21 de mayo de 2020, de Infobae: 
https://www.infobae.com/america/mundo/2020/05/17/9-

definiciones-sobre-la-pandemia-de-byung-chul-han-el-filosofosurcoreano-que-seduce-al-mundo/

rehuir el flujo de turistas. Entrevista a Byung-Chul Han, por Daniel Gamper. Recuperado el 07 de mayo de 2020, de ara.cat: https://www.ara.cat/suplements/diumenge/politic-viatjar-perquesostraurem-turistes_0_1967803205.html 2020a. ¿Vamos camino a una nueva sociedad disciplinaria? Recuperado el 09 de abril de 2020, de Clarin.com Revista Ñ Ideas: https://www.clarin.com/revista-enie/ideas/byungchul-coronavirus-lleva-nueva-sociedad-disciplinaria_0_KQsMIZCqa.html . 2012. La sociedad del cansancio. Barcelona: Herder. . 2014. En el enjambre. Barcelona: Herder.

2014a. Psicopolítica Neoliberalismo y nuevas técnicas de poder. Barcelona: Herder.

- Hajj, S. 2020. El distanciamiento social dañará el concepto de ciudadanía. EFE Redacción Internacional. Pensamiento coronavirus (Serie Especial) Recuperado el 26 de abril de 2020, de https://www.efe.com/efe/espana/mundo/hajj-saleh-eldistanciamiento-social-danara-concepto-de-ciudadania/

- Harari, Y. 2020. El mundo después del coronavirus. La Tercera. Recuperado el 24 de marzo de 2020, de https://culto.latercera.com/2020/03/19/antidoto-cooperacionnoah-harari/

- Harari, Y. 2020a. Superaremos la pandemia, pero correremos el peligro de despertar a un mundo diferente. XLSemanal. Recuperado el 19 de abril de 2020, de https://www.xlsemanal.com/personajes/20200412/yuval-noahharari-despues-coronavirus-mundo-crisis-historia.html

- Lakatos, I. 1983. "La metodología de los Programas de investigación científica". Madrid: Alianza Editorial.

- Levitt, M. 2020. El demoledor diagnóstico de un Premio Nobel sobre las cuarentenas: "No salvaron ninguna vida". Infobae. Recuperado el 28 de mayo de 2020, de https://www.infobae.com/america/mundo/2020/05/27/el- 
demoledor-diagnostico-de-un-premio-nobel-sobre-lascuarentenas-no-salvaron-ningunavida/?fbclid=IwAR1lzYeu8YmqYQVEyopsEEX2ipvJAazmmj1NAa O-AFkzLyv0OIExSICoHE8

- Melville, H. 2008. Bartleby, el escribiente. Traducción de María José Chuliá. Ilustrado por Javier Zabala. Madrid: Nórdica.

- Ministerio de Educación y Cultura. 2011. Plan Nacional de Educación 2024. Presidencia de la República. Recuperado el 07 de mayo de 2020, de https://www.mec.gov.py/cms_v2/adjuntos/2344.

- Mizrahi, D. 2020. Sociología del coronavirus: cuando la cultura de los países puede ser una ayuda o un obstáculo ante la pandemia. Infobae. Recuperado el 23 de marzo de 2020, de https://www.infobae.com/america/mundo/2020/03/22/sociologiadel-coronavirus-cuando-la-cultura-de-los-paises-puede-ser-unaayuda-o-un-obstaculo-ante-la-pandemia/

- Parker-Pope, T. 2020. ¿El virus está en mi ropa? ¿En mis zapatos? ¿En mi pelo? ¿En mi periódico? Estilos de Vida. Vivir Mejor. The New York Times. Recuperado el 01 de junio de 2020, de https://www.nytimes.com/es/2020/04/21/espanol/estilos-devida/coronavirus-ropa-contagio-pelo-zapatos-periodicoinfeccion.html?fbclid=IwAR32u0LJTI9BUNAmkaaXMvheSfK587vi fW314pUYyj6r-I2FYonaPHeowbI

- Piaget, J. 1999. La psicología de la inteligencia. Barcelona: Editorial Crítica.

- Zamora, K. 2020. El fin del siglo estadounidense y el regreso de la tentación autoritaria. El Mundo. Actualidad Política. Bajado de https://www.dw.com/es/el-fin-del-siglo-estadounidense-y-elregreso-de-la-tentaci\%C3\%B3n-autoritaria/

- Urdanibia, I. 2015. ¿Elogio de la idiocia? Kaosenlared. Recuperado el sábado 09 de mayo de 2020, de https://kaosenlared.net/elogio-de-la-idiocia/

- Zizek, S. 2020. Zizek sobre el coronavirus: un golpe letal al capitalismo para reinventar la sociedad. ljamasurf.com. Recuperado el 17 de marzo de 2020, de www.ijamasurf.com/2020/03/zizek_sobre_el_coronavirus_un_gol pe_letal_al_capitalismo_para_reinventar_la_sociedad/?fbclid=lw 
AR3Z-iDcxye6J11PQY87uxp4Cff7qEto4EbIWFI6QTdvNGQ0ulekMCcdkU

- Fernández Liria, C. 2020. La Universidad vaciada. Cuartopoder.es. Recuperado el 19 de mayo de 2020, de https://www.cuartopoder.es/ideas/2020/05/15/la-universidadvaciada-carlos-fernandez-liria/ 